\title{
Blended Learning and Student Satisfaction: An Investigation into an EAP Writing Course
}

\author{
Zainab Ibrahim Abbas
}

Higher Committee for Education Development in Iraq (HCED), Baghdad, Iraq

Corresponding Author: Zainab Ibrahim Abbas , E-mail: zainab.elc@hcediraq.org

\section{ARTICLE INFO}

Article history

Received: December 07, 2017

Accepted: January 19, 2018

Published: February 28, 2018

Volume: 9 Issue: 1

Advance access: January 2018

Conflicts of interest: None

Funding: None

Key words:

Blended,

EAP,

Interaction,

Students Satisfaction,

Writing Course

\begin{abstract}
This paper investigates students satisfaction in a blended English writing course for Academic Purposes in Iraq. Blended learning is a novel mode of approaching education and learning in Iraq so it is very relevant to attempt to determine what factors can help it its success. Its novelty comes not from its use of online platforms such as Moodle but blending the traditional face-to face approach and distance teaching in a way that foster critical thinking and ongoing participation of the students. Different factors were emphasized and investigated regarding satisfaction, among them, the instructor-student and student-student interaction, in addition to the pedagogical aspect of the course. Student's background such as their job and age and family status were not considered in this study. A modified questionnaire of student's satisfaction in an online course was used to determine the approximate of satisfaction. The result of the research helped the administration office to apply some improvements to the newly-founded Blended courses in Iraq.
\end{abstract}

\section{INTRODUCTION}

Harriman (2004) defines blended learning as a learning environment that combines various delivery modes to provide an effective learning experience for the participants. It is a blend of the strength of the face-to-face classes and online instructions and activities to achieve the certain goals of any given programs. In Garrison and Vaughan (2008)'s words, blended learning is a 'fundamental redesign that transforms the structure of, and approach to, teaching and learning.' In this paper, blended learning is a combination of activities and instructions delivered inside the once-a-week classes and the activities and assignments delivered on Moodle.

The advance of information and communications technology has influenced higher education immensely. However, this change has been very slow in the Iraqi context. The only place, so far, to foster the launch of distance and blended education has been the Higher Committee for Education Development in Iraq (HCED). The first blended courses were launched in October 2015 with a number of 145 scholarship recipients. The courses delivered EAP (English for Academic Purposes) in three levels of low-intermediate, high-intermediate and Bridge. The students were all post graduate candidates that received scholarship to study in an English-speaking country. The vision of HCED has been from the start to first acculturate the incoming students to blend easier in their destination countries but on a larger scale to popularize the new technology in higher education sector. The present research was conducted to measure the level of satisfaction of the students that participated in the writing course for the EAP program in HCED's English Language Centre (ELC).

The designers and decision makers of the institute had predicted that blended courses would be popular with participants that graduated and had started working full or part-time. As Lindsay (2004) puts it, blended courses foster technological advancements of the students, self-regulated learning methods, and social engagement and peer-interaction in its own way. Students are more involved in the learning process and take ownership of it since they have more freedom in the online space, time and engagement with the learning outcomes. Moreover, all of these may lead to satisfaction of the learning experience which in turn might determine if the students will continue with the same course or similar ones.

To define satisfaction, it can be said that participants are satisfied when their expectations are met or exceeded. Students' satisfaction is important first because it shows to the administrators that their courses are functional and second on a personal level for students, it shows if they enjoy their learning experience in a particular setting. Astin (1993) de- 
fines students' satisfaction as how they perceive their learning experiences in any learning institution. The instructor, the interconnectivity and interactivity along with technology are essential in affecting student's satisfaction.

To measure the level of satisfaction of the students, some factors will be analyzed employing the model that Moore and Kearsley (1996) suggested. In this model, learner-content, learner-instructor, and learner-learner interaction are the main factors involved in the participants' satisfaction. As what precisely interaction means, there are different opinions. For example Thurmond (2003) involves all three factors above while defining interaction as

the learner's engagement with the course content, other learners, the instructor, and the technological medium used in the course. True interactions with other learners, the instructor, and the technology results in a reciprocal exchange of information. The exchange of information is intended to enhance knowledge development in the learning environment. (4)

There is an abundant research on interaction and the following sections give a very brief description of each type.

\section{Student-Content Interaction}

As practitioners we know that when students continuously study the course contents and are involved with it, then there is learner-content interaction. According to different research in this filed, factors such as time (Atack \& Rankin, 2002), course design (Swan, 2001); and participation in online discussions board (Jiang \& Ting, 1999) affect the level of interaction of the student in the course. Learner-content interaction is also linked to other learners and instructor through class activities and online instructions.

\section{Student-Student Interaction}

Students also interact with content thought their teachers and peers since learning cannot be done in isolation. Any good learning is a joint work of sharing information between groups of people. Interaction with peers provides the opportunity for the participants to form firstly a social connection in a semi-virtual world and feel they belong to a community. Moreover, the face-to-face classes and the discussion boards enrich the learning experience.

In a fully online course, the instructor is mostly a facilitator between students and technology. In the blended courses however, the instructor still retains his traditional teaching role inside the face-to-face class by preparing materials for the class activity, grouping students and facilitating the learning environment. This interaction is still an essential factor in success of the course.

\section{Student- Instructor Interaction}

Thurmond and Wamback (2004) mention factors such as 'face-to-face interaction, timely feedback, course performance, and presence' of the instructor that influence the learner's satisfaction regarding his interaction. In addition Fredericksen et al. (2000) report a positive relation between the student's learning and their interaction with the teacher. (cited in Thurmond \& Wamback, 2004). In the blended setting, the teacher is present in two online and face-to-face settings supporting the learners via feedback on assignments or activities, replying to discussion boards prompt or messages and giving or clarifying instruction.

\section{Objectives}

The objective of this research was to measure the extent of students' satisfaction with the blended course that they participated in for six weeks. The researcher also wanted to know what are the factors that influence this satisfaction. The most important factors that were targeted in the questionnaire were the interaction between peers, teacher and the curriculum.

While other factors might influence student's satisfaction such as personal circumstances or personality of the learner and existing perceptions about learning, for the purpose of this study only the mentioned factors were investigated, for the other factors lay outside HCED's administrative control.

\section{Research questions}

The researcher intended to know the level of satisfaction of the students with their instructor, their materials and their interaction with peers.

- Do students feel more satisfied if they feel they are satisfied about their instructor's performance?

- Do students feel more satisfied if they find the content and curriculum more relevant and beneficial to them?

- Do students feel more satisfied if they feel they are connected to their peers in the same learning environment?

\section{METHODOLOGY}

The EAP writing course for bridge level lasted for 6 weeks. 25 students were divided into two classes of 13 and 12 students. The same teacher taught both classes. The same materials were used for both classes and the students had 4 hours of face-to-face contact with teacher and peers each week for one month and half. The class time was used to introduce the weekly writing objectives, present the materials and practice through hands-on and printed activities. The Moodle course was populated by the supplementary materials, quizzes and weekly assignments. All the assignments and quizzes had to be delivered and completed on Moodle and before the start of the next face-to-face class.

The instructor used a structured questionnaire to measure the satisfaction of the participants in the bended course for the AEP writing course. Questions meant to ask about student's satisfaction regarding interaction with teacher, curriculum and course design, and peers. There was an emphasis on the feedback both from the teacher and peer in affecting the participants' satisfaction. The questionnaire only used questions suing Likert scale ranging from 1 (strongly disagree) to 4 (strongly agree) and contained 21 questions.

All students received the link to the survey questions via Moodle's discussion board and message system in the final 
week- sixth week- of the program. Instructions as how to proceed with the link and questions were also included.

\section{ANALYSIS OF THE QUESTIONNAIRE RESULTS}

Reflecting on the findings presented in the summary table of the responses to the questionnaire, there are several findings that are particularly noteworthy. The first inference that we are able to draw examining the data is that the course materials, assignments and online feedbacks from instructors do indeed facilitate learning. This is substantiated by the students' answers to questions 1-4. These questions asked about modules, webpage and supplementary materials in class and Moodle, assignment projects and feedback from teacher.

Answer distributions to questions six and seven demonstrate that the online course created a sense of community among students, where they felt free to express their opinions. This can be thought of as a successful recreation of a classroom environment. This point is further validated by the 72 per cent positive responses to question 11, indicating that students were able to get clarification from their peers when needed. Moreover, 96 per cent of students agreed that the course encouraged them to discuss the covered ideas with other students.

Furthermore, the response data indicates that the Moodle course has helped students enhance some of their personal skills. Particularly, the answers to questions 13, 15 and 16 vividly illustrate that the majority of the students believe that their problem solving, written communication and critical thinking skills were incorporated and improved throughout the course.

This being said, it is important to turn to the students' overall satisfaction from the course and its effectiveness in comparison with traditional face-to-face courses. The students' feedback to question 21 highlights their overall satisfaction with the course. Replies to questions 12 and 18 further elaborate on this assertion, showing that most of the students are interested in taking another online course, and that 100 per cent of the students involved in the survey would recommend this course to others. Nonetheless, it is also crucial to point out that there is a noticeable number of students who think that they did not learn as much in the online class, as they would in a face-to-face class (question 19). Moreover, 30 per cent of the respondents believe that blended courses are generally not as effective as face to face courses.

All in all, the findings of the questionnaire clarify that the blended course was successful in effectively providing knowledge to the students with the help of feedback mechanisms, open communication, and supplementary course materials. The course also scored very high in terms of student satisfaction, but there is still a number of students who think that it was not as effective as a standard face-to-face course.

\section{CONCLUSION}

Measuring satisfaction is important for any educational institution; it helps to highlight the strong and weak points of their programs including their staff, curriculum, environment and even their policies. The interpretation of students' satis- faction may impact the adjustment in the place and foster improvements. Moreover, satisfaction may direct students to stay loyal to the program and the institution even if they have graduated and no longer study there.

On the other hand, the blended experience is a novel approach to higher education in Iraq that needs to be cared for and supported by the authorities. Since HCED is the only centre in central Iraq that has launched this type of courses, it seemed necessary to attempt to document the range of the success of this initiative through different research. There had been different surveys in the past asking for feedback and needs analysis but this was the first time that a research targeted the measure of students' satisfaction in HCED writing classes regarding their interaction.

The objective of this study had been to measure to what extent students are satisfied with their blended course and what are the factors that influence this satisfaction. The questions asked students to comment on the level of their engagement in class, with teacher and with their peers. Curriculum was also a factor that affected students' opinion about the course. The objective of the study was achieved when the results were analyzed and sent to the administration office to review and provide feedback.

The findings here provided evidence for the administration for improvement in the area of curriculum development in addition to lengthen the time of the face-to-face weekly classes. Students were satisfied with the learner-centred methods of the teacher inside the face-to-face class that shows the accuracy of adopting this method by HCED. In general, the overall satisfaction of the students with this blended program encouraged the administrators to continue offering this course to the coming and interested scholarship recipients.

\section{REFERENCES}

Astin, A.W. (1993). What matters in college? Four critical years revisited. San Francisco: Jossey-Bass

Atack, L., \& Rankin, J. (2002). A descriptive study of registered nurses' experiences with web-based learning. Journal of Advanced Nursing, 40, 457-465.

DeBourgh, G. A. (1999). Technology is the tool, teaching is the task: Student satisfaction in distance learning. Paper presented at the SITE 99: Society for Information Technology \& Teacher Education International Conference, San Antonio, TX.

http://pandora.cii.wwu.edu/showcase2001/text_only/dodd/ portfolio.htm

Fredericksen, E., Pickett, A., Shea, P., Pelz, W., \& Swan, K. (2000). Student satisfaction and perceived learning with on-line courses: Principles and examples from the SUNY learning network. Journal of Asynchronous Learning Networks, 4(2). Cited in Thurmond, V \& Wambach, Karen. (2004). Towards an understanding of interactions in distance education. Online Journal of Nursing Informatics. 8.

Garrison, D. R., \& Vaughan, N. D. (2011). Blended learning in higher education: Framework, principles, and guidelines. San Francisco: Jossey-Bass. 
Harriman, G. (2004). What is blended learning? E-Learning Resources. Retrieved in March 2016 at: http://www. grayharriman.com/blended_learning.htm

Jiang, M., \& Ting, E. (1999). A study of students' perceived learning in a Web-based online environment. Paper presented at the WebNet 99 World Conference on the WWW and Internet, Honolulu, Hawaii.

Lindsay, E. B. (2004). The best of both worlds: Teaching a blended course. Academic Exchange Quarterly, 8.

Sorden, S. S., \& Munene, I. I. (2013). Constructs related to community college student satisfaction in blended learning. Journal of Information Technology Education, 12, 251-270.

Swan, K. (2001). Virtual interaction: Design factors affecting student satisfaction and perceived learning in asynchronous online courses. Distance Education, 22, 306-331.
Thurmond, V. A. (2003). Examination of interaction variables as predictors of students' satisfaction and willingness to enrol in future web-based courses while controlling for student characteristics. Retrieved from http://www.bookpump.com/dps/pdfb/1121814b.pdf

Thurmond, V \& Wambach, Karen. (2004). Towards an understanding of interactions in distance education. Online Journal of Nursing Informatics. 8.

Wu, D., \& Hiltz, S. R. (2004). Predicting learning from asynchronous online discussions.

Journal of Asynchronous Learning Networks, 8 (2), 139-152.

Yang, Y., \& Durrington, V. (2010). Investigation of Students' Perceptions of Online Course Quality. International Journal On E-Learning,9(3), 341-361. 